\title{
The Comparative Method in Synchronic Linguistics: The Case of Word Order
}

\author{
Alessandra Giorgi \\ Ca' Foscari University of Venice
}

\begin{abstract}
In this article I discuss the comparative method in formal linguistics when applied to word order phenomena in Italian, English and German. I argue that the comparison has to rest on sound theoretical basis in order to reach interesting conclusions. These languages might prima facie all look SubjectVerb-Object - SVO - languages, with some puzzling issues arising in German. At a closer look however, I will show that English and Italian pattern together as their basic word order - i.e., SVO - goes, as opposed to German, an SOV language. Conversely, English and German pattern together with respect to a property typical, even if not exclusively so, of Germanic languages, i.e. Verb Second.
\end{abstract}

Key words: word order, syntax, Verb Second, Romance, Germanic.

\section{Introduction}

In this article, I provide a brief introduction to the comparative method and to linguistic typology, discussing some issues concerning the basic word order of Italian, English and German. I will show that in the comparison among languages, raw data are not enough to provide a satisfactory classification and that a formal model is required to make sense of the various existing orders, together with several phenomena, which would otherwise go unexplained.

Language is often seen as a means of communication shaped by our culture and history. It is certainly an incontrovertible fact that language, by enabling a speedy and efficient communication with our fellow humans, provided us with a huge evolutionary advantage. However, it is also quite clear that language is a 
very important cognitive ability, defining humans as special among all living beings. Human language has no rival among the animal communication systems, both qualitatively and quantitatively, no matter how sophisticated such systems might look.

Therefore, in order to understand the nature of language and its manifestations, it is necessary to study on one side, the history and the relevance of culture in language, and on the other, the properties of our cognitive system, enabling the language faculty. In order to do that, a theoretical framework of investigation, connecting language with psychology and neurology is necessary. The framework I will refer to in this article is the one developed by Chomsky $(1995,2002)$ and scholars.

The issues I am going to consider in the following sections illustrate this dual nature of language: cultural and cognitive. By means of the comparative method and the theoretical generative framework, I will show that English and Italian pattern together with respect to their basic word order, i.e. SVO, as opposed to German, an SOV language. Conversely, English and German pattern together with respect to a property typical of Germanic languages, i.e. Verb Second. Basic word order plus Verb Second properties will be shown to account for a wide set of data, which would otherwise remain unexplained.

\section{Word Order and Linguistic Typology}

Scholars of linguistic typology have studied word order variations quite extensively. ${ }^{1}$ The typologists' goal is a better understanding of the distribution of the properties of languages, and in particular of how languages vary and what correlations can be found among their different features.

As defined by Comrie, Dryer and Haspelmath (2013:1), linguistic typology can be defined as "the systematic study of the ways in which the languages of the world vary structurally and of the limits to this variation." They go on providing the following example (ibidem): "For instance, we may want to know whether languages with a particular word order in the clause, say subject-verbobject as in English (the farmer killed the duckling), are found only in one part of the world, whether they are distributed more or less evenly across different 
parts of the world, or whether some in between scenario holds."

In this work, I will compare the basic word order of Italian, German and English, taking into account not only main clauses, but also more complex structures, constituting potential problems for a coherent classification.

With respect to word order variation, the figures provided by WALS are the following: ${ }^{2}$

Table 1

\begin{tabular}{|l|l|l|}
\hline SOV & 565 & Japanese, Indo-Aryan languages \\
\hline SVO & 488 & English, Romance \\
\hline VSO & 95 & Arabic, Celtic \\
\hline VOS & 25 & Malagasy, Fijian \\
\hline OVS & 11 & Hixkarayana (Amazon) \\
\hline OSV & 4 & Xavante (Mato Groso) \\
\hline No Dominant order & 189 & German, Armenian \\
\hline
\end{tabular}

As can be seen, the number of languages considered by WALS is quite extensive. The majority of languages happen to be either SOV or SVO, with a considerable group of verb-initial languages, whereas the three other groups are relatively small. Furthermore, there is a large group of languages classified a no dominant order. Note that in this table, English and Romance languages, therefore Italian as well, are put together in the same group, whereas German falls in the no-dominant-order slot.

Linguists have amply discussed word order issues and it will be impossible for me to review here the literature on the relevant issues. As I pointed out above, I will limit my contribution to the comparison of Italian, English and German with respect to certain word order phenomena, in order to show that a theoretical framework actually permits a better understanding of certain phenomena.

This table raises at least two questions. The first one concerns the relatively small number of languages exhibiting VOS, OVS and OSV orders; the second concerns the languages with no dominant order and what that exactly means. 
In this article, I will have nothing to say with respect to the first issue, whereas I will consider the second one, as far as German is concerned. ${ }^{3}$

\section{The Order Subject-Verb-Object}

In defining the basic word order, one has to look at the order of words in sentences expressing assertions, when uttered in absence of any previous context. An assertion, roughly speaking, is a declarative sentence - as opposed to a question, an exclamation, or an order, i.e. a content expressed by a speaker with the intent of sharing a certain knowledge with her audience. In order to check the basic word order, it is important that no linguistic or extra-linguistic context is provided - i.e. that the sentence is uttered out-of-the-blue, so that the informational properties, such as given information vs. new one, do not constrain the syntactic form of the utterance. It is a well-known fact, that informational properties have an important influence on word order, but in this work I will put this issue aside. Hence, a simple way of classifying languages is to consider the ordering in sentences with transitive verbs, i.e. sentences constituted by a subject, an object and a verb, as in Table 1 above. For instance, to compare Italian, English and German we can look at examples such as the following ones: ${ }^{4}$

(1) Gianni mangia una mela(Italian)

(2) John eats an apple (English)

(3) Hans isst einen Apfel (German)

In these examples, the transitive verb eat appears with the animate subject, John, and the inanimate object an apple. In this case, the three languages exhibit the order Subject-Verb-Object. These are declarative sentences, which can be uttered out-of-the-blue without the necessity of a previous context. ${ }^{5} \mathrm{In}$ other words, in order for the sentences in (1) - (3) to be felicitous, there is no need of a previous mention of an eating event, nor of its participants, John and an apple.

Hence, according to this piece of evidence, Italian, English and German should be taken to share the basic word order SVO. If this is the case, this 
should be true independently of the kind of subject, object and verb appearing in the sentence.

This seems to be correct, as far as subject and object are concerned. For instance, instead of the proper noun John, we could have the nominal expression the girl, and the apple could be substituted by any other eatable object. Consider for instance the following examples:

(4) La ragazza mangia una pera (Italian)

(5) The girl eats a pear (English)

(6) Das Mädchen isst eine Birne (German)

However, the same does not apply with respect to the position of the verb, when the verbal form is not a syncretic one.

\section{The Position of the Verb in German}

We know that in Italian, English and German, as in many other languages of the world, verbal forms can be either synthetic or periphrastic. The present tense in the examples above is a synthetic form, constituted by the verb plus a suffixal ending - mangi-a; eat- $s$; iss- $t^{6}{ }^{6}$ A periphrastic form is constituted by a participle and an auxiliary. The participle can be invariant or have an inflectional ending, according to the properties of the specific language. The present perfect is typically a periphrastic form: Italian ha mangiato (Aux.3.sing Part); English have eaten (Aux.3.sing Part); and German hat gegessen (Aux.3.sing Part). As can be seen, the glosses of the three forms are exactly the same, and the auxiliary is always have. However, word order does not always remain the one we see with the present tense. Consider the following examples:

(7) La ragazza ha mangiato una pera (Italian)

(8) The girl has eaten a pear (English)

(9) Das Mädchen hat eine Birne gegessen (German)

In Italian and English, the periphrastic form occupies the same position as the synthetic one, i.e. in between the Subject and the Object, whereas in 
German the auxiliary (hat) follows the subject, but the participle (gegessen) occurs sentence-finally. German therefore, raises an issue with respect to its classification according to its word order. If we consider as relevant the position of the auxiliary, we end up with SVO; if on the contrary, we consider as crucial the position of the participle, we have an SOV order.

As illustrated in table 1, German as a matter of fact, is classified as a no dominant order language, given this kind of issues. However, this conclusion seems quite unsatisfactory, because it does not explain why German turns out to be different from Italian and English, and why a periphrastic form exhibits a different word order with respect to a synthetic one. Hence, a simple classification of the reciprocal order of Subject, Object and Verb, constitutes an important starting point, but cannot be considered a sufficient account for the word order properties of a language.

As a first consideration, note that even in Italian and English it cannot be simply claimed that the periphrastic form ha mangiato and has eaten occupy the same slot as the syncretic verbal form. Consider the following examples:

(10) La ragazza ha certamente mangiato una pera

(11) The girl has certainly eaten a pear

Example (9) above shows that in German the object (eine Birne /a pear) can appear between the auxiliary and the participle. Examples (10) and (11) show that in Italian and English an adverb, in this case certainly, can appear in between, hence in all the languages discussed here the two parts of the present perfect can be separated by some sort of linguistic material.

For this reason, it seems that the label Verb for periphrastic forms is inadequate: it is necessary to distinguish between the two parts of the verbal expression: the auxiliary and the participle. The auxiliary conveys the temporal information, so that we can have a present perfect, as in the examples above, or a past perfect - had eaten, where had is a past verbal form - and in Italian also a compound future, avrà mangiato (he will have eaten), were the auxiliary avrà (will have) appears with future morphology. The participle conveys the lexical 
information, i.e. it identifies the event the sentence is about. In the examples above, the event is an event of eating. Conversely, when the verbal form is a synthetic one, both the temporal properties and the lexical ones are realized by the same word.

\section{More about German}

Word order in German, and in other Germanic languages as well, exhibits other interesting properties. The position of subject and object given in (9) can be inverted, maintaining the same meaning, yielding the following sentence:

(12) Die Birne hat das Mädchen gegessen

The pear has the girl eaten

The girl ate the pear

The sentence can begin with an adverb as well, as in the following case:

(13) Gestern hat das Mädchen die Birne gegessen

Yesterday has the girl the pear eaten

Yesterday the girl ate the pear

If an indirect object appears in the sentence, it can precede the auxiliary as well:

(14) Dem Mädchen hat Hans ein Buch gegeben

The girl.dat has Hans a book. acc given

Hans gave a book to the girl

Hence, it seems that a variety of word orders are available in German. However, this does not mean that there are no constraints. The following orders are not available (I signal the non-availability of a certain order with a $\left.{ }^{(*)}\right):^{7}$

(15) *Hat die Birne das Mädchen gegessen Has the pear the girl eaten 


\section{(16) ${ }^{*}$ Hat gegessen die Birne das Mädchen Has eaten the pear the girl}

The verb cannot occupy the first position, with or without the participle after it. Consider now the following examples, where the participle and the auxiliary are adjacent and appear at the end of the sentence:

(17) *Die Birne das Mädchen hat gegessen

The pear the girl has eaten

(18) ${ }^{*}$ Die Birne das Mädchen gegessen hat

The pear the girl eaten has

(19) ${ }^{*}$ Das Mädchen die Birne hat gegessen

The girl the pear has eaten

(20) *Das Mädchen die Birne gegessen hat

The girl the pear eaten has

These sentences are all ungrammatical, in that the auxiliary cannot appear at the end of the sentence together with the participle, neither preceding it, nor following it. Consider also that the reciprocal order of subject and object is irrelevant. ${ }^{8}$ Finally, of the two parts constituting the verb, only the auxiliary can appear on the left, and not the participle:

(21) * das Mädchen gegessen die Birne hat

The girl eaten the pear has

(22) * die Birne gegessen das Mädchen hat

The pear eaten the girl has

In these cases as well, the reciprocal order of subject and object is not relevant.

Linguists long ago proposed a generalization called Verb Second - V2. ${ }^{9}$ In all the cases judged as grammatical by native speakers, the temporalized part of the verb appears in the second position. This is true both for a synthetic verbal 
form, such as isst (eats), in sentence (6), and for the auxiliary in sentences (9) and (12)-(14), where items other than the subject - object, indirect object and adverb - appear in the first position. All other possibilities are ruled out, as shown in examples (15)-(22). ${ }^{10}$

Following this reasoning, the supposed SVO order of example (6) - Das Mädchen isst eine Birne (the girl eats a pear) - turns out to be very different from the SVO order of Italian and English. In Italian and English there is no V2 pattern in declarative sentences and the participle does not follow the object, as exemplified by the following examples:

(23) *Gianni ha la mela mangiato

Gianni has the apple eaten

(24) John has eaten an apple

(25) *John has an apple eaten

On the contrary, (22) and (23) would be acceptable word order in German.

However, with respect to the similarities between Italian and English, there is still an important point. All Germanic languages - even if with minor differences - share the Verb Second pattern, with the apparent exception of English, whereas Romance languages do not. It is well-known that English in the course of history underwent the influence of Romance, but one can wonder if English really is an exception to the general properties of Germanic. In the next section I will briefly consider this issue. ${ }^{11}$

\section{A Closer Look into Word Order in English}

I illustrated above that word order in English declarative sentences is the same as in the Italian one. But what can be said about non-declaratives? Traditional grammars of English often mention the so-called subject inversion rule: in some types of sentences the subject appears after the verb. For the sake of completeness, note also that in English, contrary to Italian, in declarative sentences a definite subject, such as for instance a proper name, can never appear post-verbally, as shown in the following examples: ${ }^{12}$ 
(26) Ha telefonato Gianni (Italian)

Has called Gianni

Gianni called

(27) John called

(28) ${ }^{*}$ Called John

Consider first word order in interrogative sentences, compared with the declarative one:

(29) John has eaten a sandwich

(30) What has John eaten?

(31) John has given a book to Mary

(32) To whom has John given a book?

(33) John has gone to London

(34) Where has John gone?

In all the interrogative cases, the subject must appear after the auxiliary. ${ }^{13}$

When the verb of the corresponding declarative sentence is not a periphrastic form, an auxiliary is created - this is the phenomenon traditionally called do insertion:

(35) John ate a sandwich

(36) What did John eat?

(37) John gave a book to Mary

(38) To whom did John give a book?

(39) John went to London

(40) Where did John go?

The verb in these cases is a periphrastic form, constituted by the auxiliary do followed by an infinitive.

In all the interrogative cases listed above, the auxiliary does indeed occupy the second position and the pattern looks very similar to the one given for 
declarative sentences in German. The first position in fact is occupied by an interrogative item, expressing an object, an indirect object or an adverb, exactly as in the German cases, modulo the non-declarative status of the sentence.

There are other kinds of sentences requiring subject inversion, as for instance sentences beginning with a negative item, as in the following cases:

(41) Never has John failed an examination

(42) Seldom has John failed an examination

The examples in (41) and (42) have an emphatic flavor.

Concluding these remarks, it looks like there are indeed some cases of V2 in English as well, but only in certain cases. These phenomena have been called in the literature. Most notably by see Rizzi (1996) residual Verb Second phenomena, being vestigial of a previous stage of English exhibiting full V2. Hence, even if English is classified as a SVO language, on a par with Italian, it still shows Germanic-like features in its word order, such as the verb second constructions illustrated above.

\section{English and Italian Declarative Sentences}

In this section I will briefly discuss the evidence provided above by introducing some theoretical notions.

One of the problems at this point is to understand what English and German have in common, that is, why English interrogative sentences and German declarative ones share the same property of V2. In order to provide an answer to this question, it is necessary to introduce some linguistic theory concerning the syntactic structure of the sentence. Syntax is the branch of linguistics dealing with word order phenomena and it rests on the basic assumption that a sentence is not just a sequence of words, but is organized in a structure.

Let us consider a sequence judged by a native speaker as a sentence belonging to her language, for instance, John sleeps. This sequence is not only a string composed of a noun $(\mathrm{N})$ and a verb $(\mathrm{V})$, but is much more, in that it is a 
predicative structure composed of subject, John, ad a predicate, sleeps. The same can be said of much longer and more complex sequences, such as, the boy I met yesterday is eating an apple in the garden. In this case as well, there is a predicative structure, where the subject is much longer and is constituted by the whole sequence the boy I met yesterday-including the noun boy, preceded by an article and followed by a relative clause - and the predicate is constituted by is eating an apple in the garden - including the verb, the object and a locative adverb.

Therefore, simplifying a quite complex issue, we can conclude that no matter how long a declarative sentence is, it is constituted by a subject and a predicate, and that the subject (usually) includes a noun and the predicate (usually) includes a verb. The subject and the predicate are phrases, or constituents. ${ }^{14}$

To represent this generalization, the subject and the predicate are put into brackets and labeled Noun Phrase, NP, and Verb Phrase, VP, respectively; their sequence gives rise to a sentence, $\mathrm{S}$. Hence, a declarative sentence can be represented by means of the following structure:

(43) $\left[\mathrm{s} \quad[\mathrm{NP} \quad \ldots \mathrm{N} \ldots]\left[\begin{array}{lllll}\mathrm{vP} & \ldots \mathrm{V} & \ldots\end{array}\right]\right.$

The dots on the right and on the left of $\mathrm{N}$ and $\mathrm{V}$ signal that there can be other material inside the subject Noun Phrase and the Verb Phrase, besides the noun and the verb. Therefore, according to this proposal, the example discussed above: the boy I met yesterday is eating an apple in the garden has the following structure:

(44) [ s [NP the boyn I met yesterday] [vp is sleepingvin the garden] ]

The noun boy is called the head of the Noun Phrase and the verb sleep is the head of the Verb Phrase. This structure however, is not adequate to capture the phenomena illustrated above and should be made a little more complex. As 
pointed out earlier, in fact, the auxiliary and the verb cannot be simply labeled together as $\mathrm{V}$, since they can be separated by linguistic material, and appear in non-contiguous positions in the sentence, both in Italian, where they can be separated by adverbs (as can be the case in English as well) and in V2 constructions in German and English, where the auxiliary must occupy the second position in the sentence. The auxiliary, therefore, must be granted a certain degree of autonomy with respect to the participle.

Recall that the auxiliary expresses the temporal properties, which in the synthetic forms are realized by means of verbal morphology on the head V: love + past $\rightarrow$ lov-ed. Hence, we can label the auxiliary as tense, assigning it to the category T. Finite verbal forms are constituted by a temporal part and a lexical part. In the periphrastic cases, the two are realized as separate items: the temporal part is realized by the auxiliary and the lexical one by the participle. When the verbal form is synthetic, the temporal morpheme is attached to the lexical verb.

Summarizing, has eaten, i.e. Auxiliary+participle, realizes T and V; loved, i.e. V+past, realizes $\mathrm{V}$ and $\mathrm{T}$.

Let us consider first the forms with the auxiliary. From the discussion above, it follows that $\mathrm{T}$ cannot be realized together with $\mathrm{V}$. The proposal in generative grammar is that $\mathrm{T}$ is an autonomous head, located on the left of the Verb Phrase. Hence, the structure is the following: ${ }^{15}$

$$
\left.\left[\begin{array}{llll}
\mathrm{NP} & \ldots \mathrm{N} & \ldots
\end{array}\right]\left[\begin{array}{llll}
\mathrm{T} & \mathrm{vP} & \ldots & \mathrm{V}
\end{array}\right]\right]
$$

The structure assigned to a sentence such as John has failed the examination, is therefore the following:

(46) [ [NP John ] [ hast [vp failedv the examination ] ] ]

As can be seen in (45) and (46), the auxiliary is labeled T and its constituent includes the Verb Phrase. Importantly, $\mathrm{T}$ and $\mathrm{V}$ do not share the same position in the structure, since $\mathrm{T}$ appears on the left of the Verb Phrase. In this way, the apparent discontinuity observed in sentences (10) and (11) above, is not 
surprising any more. In fact, by means of this representation, the auxiliary and the participle can be separated by an adverb, as for instance in a sentence such as: John has certainly failed the examination. This way, at least part of the anomalies observed above, can be accounted for.

When the verbal form is synthetic, the complex verb $+\mathrm{T}$ occupies the position $\mathrm{T}$, instead of $\mathrm{V}$. I provide here an Italian example:

(47) Gianni mangiava un panino

Gianni eat.past a sandwich

Gianni was eating a sandwich

The form mangiava (ate) can be decomposed in mangia-va (eat+ past) and is represented as follows: ${ }^{16}$

(48) [ [NP Gianni ] [ mangia-va V+T [vp un panino ] ] ]

In this case, the whole verb, which includes $\mathrm{T}$, appears on the left of the Verb Phrase.

To conclude this brief section, it is possible to say that the order SVO observed in Italian and English is actually better represented as the underlying order Subject - Tense - Verb - Object, where Tense and Verb can be bound together, when the verbal form is a synthetic one.

\section{German Verb Second}

Let's analyze again the German sentences not beginning with a subject, as the one in (12), reproduced here for simplicity:

(49) Die Birne hat das Mädchen gegessen

The pear has the girl eaten

The girl ate the pear

In this case, the subject, das Mädchen, follows the auxiliary, whereas according to the structure provided above in (45), it should precede it. In that 
structure there is actually no way of locating the various items, as seen in (49). Recall also that it is not just the object which can precede the auxiliary, but whatever other phrase - an indirect object and an adverb - could as well.

As a first consideration, observe that the participle always appears at the end of the sentence. Hence, if the participle belongs to category $\mathrm{V}$, then, according to the language classification illustrated in section 1, German should be a Subject Object - Verb language, in spite of the fact that we see sentences like Hans isst einen Apfel (Hans eats an apple), where the verb precedes the object. As proposed above, this sentence as well can be analyzed as a case of V2, where the phrase preceding the temporalized verb in second position happens to be the subject.

In order to assign a structure to example (49), it is necessary to consider what happens in embedded clauses. German introduces embedded clauses, for instance clauses complements of a saying verb, with the particle dass, which is roughly equivalent to English that. These particles are called Complementizers and labeled C. Consider the following example:

(50) Hans sagte, dass Marie einen Apfel gegessen hat

Hans said that Marie an apple eaten has

Hans said that Marie ate an apple

In this example, there is a main clause has sagte (Hans said) followed by the Complementizer dass (that) and a subordinate clause, exhibiting the order Subject - Object - Verb. Hence, no Verb Second takes place in this case.

I will not discuss here the position of the auxiliary in the embedded clause, since it would lead us too far away from the present discussion. I only want to point out that the order in the subordinate clause changes when the complementizer is absent. Consider the following example:

(51) Hans sagte Marie hat einen Apfel gegessen

Hans said Marie has an apple eaten

Hans said that Marie ate an apple 
In this case, the order of the subordinate clause is the one found in main clauses: Marie hat einen Apfel gegessen (Marie has an apple eaten). These sentences exhibit the V2 pattern, as shown by the following example:

\section{(52) Hans sagte einen Apfel hat Marie gegessen}

Hans said an apple has Marie eaten

Hans said that Marie ate an apple

The order of the embedded clause in (51) is Subject - Auxiliary - Object Participle, which is the same one as the one in example (9) above. The order in example (52) is Object - Auxiliary - Subject - Participle, which is the same as the one of example (12).

Hence, the generalization is the following: German subordinate clauses are verb final, when the complementizer dass (that) is present, otherwise they follow the Verb Second pattern. Structurally, the complementizer and V2 are in complementary distribution: embedded sentences show either the one or the other, contrasting with simple sentences, where V2 is always obligatory. In other words, dass and the temporalized verb, either the full verb, or the auxiliary, are in complementary distribution. According to the literature on the topic, this happens because they compete for the same structural position, which cannot be filled twice. This principle can be formally stated as follows: ${ }^{17}$

If $X$ and $Y$ are in complementary distribution, they occupy the same position in the structure.

Going back to the structure to be assigned to V2 clauses, given (53), we can conclude that the Auxiliary - i.e., more abstractly, Tense - in V2 sentence occupies the same position as the Complementizer - dass (that). In main clauses, we do not see a complementizer, but the hypothesis is that the same holds in those cases as well.

It is clear, as argued in the literature, or instance by Rizzi (1997), that the position of the Complementizer dass in subordinate clauses lies externally to the 
predicative structure, since it precedes all the arguments, the subject included. The syntactic area on the left of the subject is usually called the left periphery of the clause. When the clause is a subordinate one, the Complementizer appears in this position, or, otherwise, the temporalized Verb - realized as an auxiliary, in the case of periphrastic verbal forms - appears there. The verb in V2 position is preceded by a phrase, and this is an obligatory property, as illustrated by the examples discussed above.

Therefore, we can conclude that German has indeed a dominant word order: German is a SOV language, where Verb Second applies obligatorily in all cases (with the exception of the clauses introduced by a Complementizer). This is a welcome conclusion, since it provides an explanation for the observed word order variations.

The structure to be assigned to V2 clauses in German is therefore the following (where S stands for Sentence):

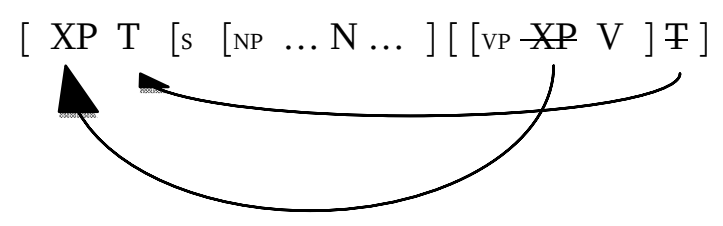

The auxiliary originates in final position, and ends up in the left periphery, preceded by a phrase, in this case an object originating inside the VP:

(55) [Einen Apfel hat[s [NP das Mädchen] [ [vp einen Apfelgegessen] hat]]]

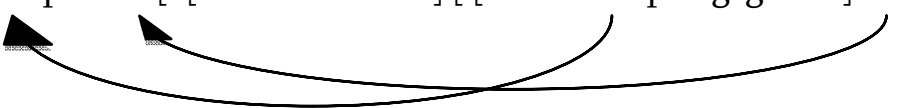

an apple has the girl eaten

When the sentence is a subordinate one, if the left periphery is occupied by dass, no V2 is possible, because dass and hat compete for the same position. Hence, the non-V2 structure is the following one: 
(56) ... [ dass [s [NP das Mädchen ] [ [vp einen Apfel gegessen ] hat ] ] ]
that the girl an apple eaten has

\section{English Interrogative Clauses}

As illustrated above, in section 5, English exhibits residual Verb Second phenomena in interrogative clauses.

The hypothesis is that the structure is exactly identical to the one provided above, with the only difference that the XP is an interrogative item. The structure for English is the following one (note that in English Tense appears on the left of VP, and not on the right as in German. INT stands for Interrogative):

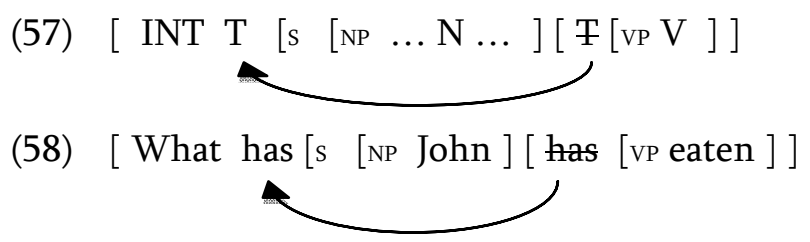

The same structure is available in case of initial negation, or in the other cases triggering V2.

\section{Conclusion}

According to the literature on the issue, V2 is characteristic of the Germanic languages, with Modern English having only a residual form of V2. Even if V2 is a relatively rare phenomenon among the languages of the world, it is certainly not limited to a single language group. As pointed out by Holmberg (2015), among the modern Romance languages, only some of the Rhaetoromance languages exhibit the V2 properties. However, V2 was characteristic of many, or even all, Medieval Romance languages. Among the modern Celtic languages, we find Breton, but it was earlier more widespread at least among the Brythonic Celtic languages. Among the Finno-Ugric languages, Estonian shows V2. Among the Slavic languages, Sorbian is reported to have V2. The Indo-Aryan language Kashmiri is a V2 language, as are two dialects of Himachali, also Indo-Aryan and adjacent to Kashmiri. Interestingly, word order 
phenomena in all these languages can be accounted for by means of the proposals illustrated above.

Some of these languages, like German, are basically SOV and other ones, like English are SVO; V2 combines with the basic word order to give rise to a variety of observable word orders.

The simple theoretical apparatus presented in this work permits to account for several complex cases, tracing back some odd and unexplained phenomena, such as for instance word order variations in main and subordinate clauses in German and subject inversion in English, to more general properties. This is a welcome result because it permits us to provide a more accurate description and classification and, more importantly, to reduce apparently unpredictable differences among languages to predictable patterns.

Also, it seems to me that the phenomena I just discussed provide a clear example of the interaction between the cultural nature of language and its cognitive foundations. Languages do not vary indiscriminately, but along precise dimensions, which can be captured both investigating their diachronic properties, i.e. their cultural heritage, and their synchronic ones. Under this perspective, we can say that Modern English has subject inversion, i.e. residual Verb second, because from a diachronic point of view, on one side, it is a Germanic language, and, on the other, it underwent strong influences from Romance, as pointed out by Roberts (1993). However, the rules of grammar concerning Verb Second phenomena are very general and hold in a variety of languages, even if typologically they are very far from the Germanic ones.

Future research on word order and Verb Second phenomena should proceed along these lines, investigating both the diachronic evolution of languages and their synchronic properties. Moreover, the various word orders should also be investigated with respect to their informational value in relation with the context. It is in fact a very general observation that word order, together with intonation, signals different informational properties with respect to the new or given status of the various part of the sentence. 


\section{Notes:}

1. On linguistic typology, cf. among the others Greenberg (1963), Comrie (1989), Dryer and Haspelmath, (2013). For a discussion of word order universals in a generative framework, see among the others Cinque (1999).

2. See Dryer (2013, http://wals.info/chapter/81 [Accessed on 2019-08-29].

3. On word order in Armenian in a generative framework, see Giorgi and Haroutyunian (2016).

4. In this work, I am not considering the contribution of the participle to the meaning of the verbal form. The participle adds an aspectual value, which must be combined with the aspectual one. On the notion of aspect, see Comrie (1976) and Giorgi and Pianesi (1997), for the properties of temporal forms in embedded clauses, see Giorgi (2010). Also, I am disregarding the aspectual value of the present tense in English. In order to be equivalent in meaning to the Italian form, the English verb in this case should appear as a progressive periphrasis: is eating. For the sake of the argument, however, I will use the present tense in English as well.

5. Irrelevantly, a minimal context is always required, in that for instance, the proper name John must refer to an individual identifiable both by the speaker and the addressee. This shared knowledge is often called common ground.

6. I am not taking into account here the possible irregularities of the verbal inflection, because they are not relevant for the purposes of the present discussion. Hence a verbal form like ate, is taken to be eat + past, not differently from any other regular verb.

7. In generative grammar the symbol (*) is used to signal that a certain string is not considered a good sentence by a native speaker, i.e. that the speaker does not recognize the string as a sentence belonging to her language. This is a grammaticality judgment by the speaker on the form of the sentence, independently of its comprehensibility, namely: 'This is not how it is said'. Accordingly, the sequence is identified as ungrammatical.

8. In section 6.2 I will go back to sentences (18) and (20), since this order is actually admitted in subordinate clauses. 
9. See Den Besten (1983). See also Holmberg (2015) for a discussion of the state of the art on this issue.

10. In the grammatical tradition of German, these regularities had obviously been observed. As a matter of fact, the terms Vorfeld, Mittelfeld, Nachfeld refer respectively: to the items that precede the temporalized verb, i.e. the auxiliary, to the part of the sentence between the auxiliary and the participle and to the items following the participle, if there are any.

11. It is also well-known that word order in Romance languages has not always been the same. For instance, Old Italian was a V2 language, see Poletto (2014).

12. In English, an indefinite subject can appear post-verbally in certain constructions:

i. There arrived three men

However, a discussion of the properties of indefinites in English lies beyond the limits of this work. Note also that the sentence in (28) could not be rescued by the insertion of a preverbal expletive pronoun:

ii. *It/there called John

In some cases, the item there, when corresponding to a locative interpretation, can be accompanied by an inverted subject:

iii. Here is your sandwich!

The sentence in (iii) can assimilated to the other cases I am discussing in this section.

13. Note that in Italian the subject can appear post-verbally, as in (26), but cannot appear in between the auxiliary and the participle, as is the case in English:

i. *Ha Gianni telefonato (it.)

Has Gianni called

Therefore, English so-called subject inversion is a different phenomenon with respect to the post-verbal subject in Italian and other Romance languages. 
14. In the text I am simplifying a complex situation. Even if most sentences have nominal subjects, there are some cases where the subject can be nonnominal, as in the following Italian case:

i. Che Maria sia partita preoccupa Gianni

That Maria left worries Gianni

Che Maria sia partita (that Maria left) is the subject of the sentence and is itself a sentence. Moreover, in some languages, such as for instance Latin, it is possible to have sentences without an explicit verbal form:

ii. Caesar imperator

Caesar emperor

'Caesar is the emperor'

In these cases the interpretation of the copula is always as a present tense.

15. As I will briefly point out in the text, $\mathrm{T}$ is on the right of the VP in German, but this property only shows up in subordinate clauses. Consequently, the structure in (45) is appropriate for English, but should look as follows in German:

i. $\left.\left[\begin{array}{llll}{[\mathrm{NP}} & \ldots \mathrm{N} & \ldots\end{array}\right]\left[\begin{array}{llll}\mathrm{vP} & \ldots \mathrm{V} & \ldots\end{array}\right] \mathrm{T}\right]$

16. I am disregarding here several theoretical and technical points, for the sake of simplicity. The different positions of the verb when syncretic and periphrastic have been widely discussed in the literature. For a comparison between Germanic and Romance, see Roberts (1993).

17. This proposal was discussed for the first time by Den Besten (1983). See also Holmberg and Platzack (1995) and Holmberg (2015) for a review of the current literature.

\section{References:}

1. Besten, D.H. (1983) On the Interaction of Root Transformations and Lexical Deletive rules. // On the formal nature of the Westgermania / Ed. by W. Abraham. pp. 47-131. Amsterdam: John Benjamins.

2. Chosmky, N. (1995) The Minimalist Program. Cambridge MA: MIT Press.

3. Chomsky, N. (2001) Derivation by Phase. // Ken Hale: a Life in Language. / Ed. by M. Kenstowicz. 1-52. Cambridge, MA: MIT Press. 
4. Cinque, G. (1999) Adverbs and Functional Heads: a Cross-Linguistic Perspective. New York: OUP.

5. Comrie, B. (1976) Aspect: An Introduction to the Study of Aspect and Related Problems. Cambridge: CUP.

6. Comrie, B. (1989) Language Universals and Linguistic Typology. Oxford: Blackwell.

7. Comrie, B; Dryer, M.; Gil, D.; Haspelmath, M. (2013) Introduction. // The World Atlas of Language Structures Online. / Ed. by M. Dryer, and M. Haspelmath, Leipzig: Max Planck Institute for Evolutionary Anthropology. Available at: <http://wals.info/chapter/s1> [Accessed August 2019].

8. Dreyer, M. and M. Haspelmath, (eds.) (2013) The World Atlas of Language Structures Online. Leipzig: Max Planck Institute for Evolutionary Anthropology. Available at: <http://wals.info > [Accessed August 2019].

9. Dreyer, M. (2013) Order of Subject, Object and Verb. // The World Atlas of Language Structures Online. / Ed. by M. Dryer, and M. Haspelmath, Leipzig: Max Planck Institute for Evolutionary Anthropology. Available at: <http://wals.info/chapter/81> [Accessed August 2019].

10. Giorgi, A. and Pianesi, F. (1997) Tense and Aspect: from Semantics to Morphosyntax, New York: OUP.

11. Giorgi, A. (2010) About the Speaker: towards a Syntax of Indexicality, Oxford: OUP.

12. Giorgi, A. and Haroutyunian, S. (2016) Word Order and Information Structure in Modern Eastern Armenian. // Journal of the Society for Armenian Studies. Vol. 25, pp. 185-200.

13. Greenberg, J. (ed.) (1963) Universals of Language, Cambridge MA, MIT Press.

14. Holmberg, A. and Platzack, C. (1995) The Role of Inflection in Scandinavian Syntax. New York: OUP.

15. Holmberg, A. (2015) Verb Second. // Syntax-Theory and Analysis. An International Handbook. / Ed. by T. Kiss \& A. Alexiadou. Vol. 1. pp. 242283. Berlin: Mouton de Gruyter. 
16. Poletto, C. (2014) Word Order in Old Italian. New York: OUP.

17. Rizzi, L. (1996) Residual Verb Second and the Wh-Criterion. // Parameters and functional heads: Essays in comparative syntax, pp. 62-90. / Ed. by A. Belletti and L. Rizzi. Oxford: OUP.

18. Rizzi, L. (1997) The Fine Structure of the Left Periphery. // Elements of Grammar: Handbook of Generative Syntax. pp. 281-337. / Ed. by L. Haegeman. Dordrecht: Kluwer.

19. Roberts, I. (1993) Verbs and Diachronic Syntax: a Comparative History on English and French. Dordrecht: Kluwer.

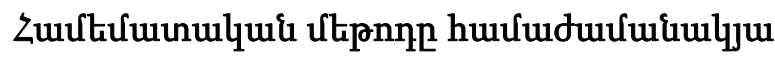

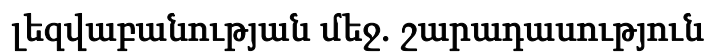

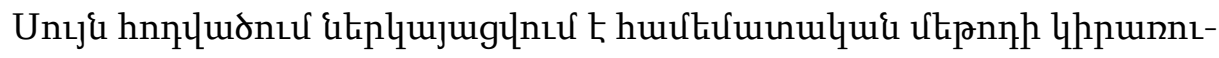

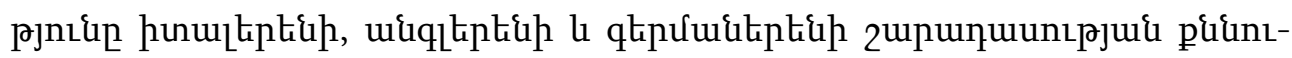

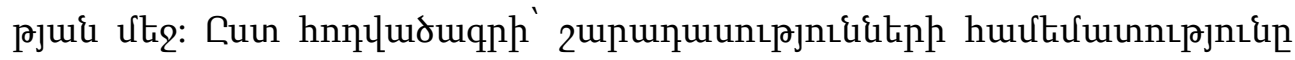

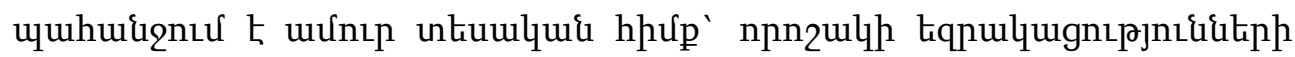

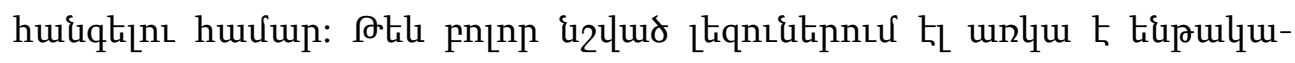

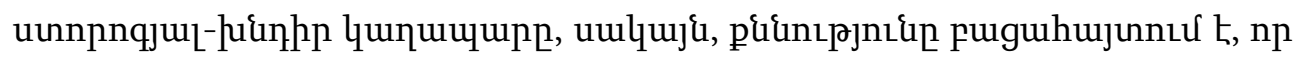

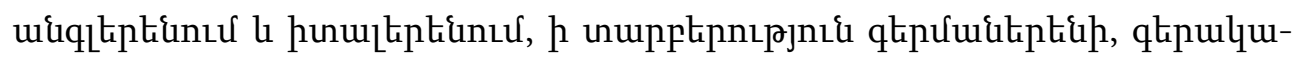

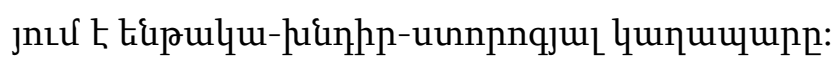

Received by the Editorial Board 08.09.2019

Recommended for publication by the reviewers 1.10 .19

Accepted for print 30.01.2020 